\title{
O USO DO BIOFERTILIZANTE EM SOLOS AGRÍCOLAS DO CERRADO DA REGIÃO DO ALTO PARANAÍBA (MG)
}

\author{
THE USE OF BIOFERTILIZERS IN CERRADO'S AGRICULTURAL SOILS OF \\ ALTO PARANAIBA REGION (MG)
}
USO DEL BIOFERTILIZANTE EN LA AGRICULTURA DE LAS ZONAS DEL SUELO DE CERRADO EN LA REGIÓN DE ALTO PARANAÍBA (MG)

\author{
Rodrigo Cavalcanti do Nascimento - Universidade Federal de Uberlândia - Uberlândia - Minas Gerais - Brasil \\ rodricn80@gmail.com
}

\begin{abstract}
Resumo
A partir da implementação do projeto integrado na suinocultura, a região do Alto Paranaíba (MG) vem-se deparando com uma nova reestruturação no setor, tendo como consequência a instalação de diversas empresas do agronegócio. Porém, a região vem sofrendo um forte impacto ambiental causado pelo acúmulo de dejetos de suínos e pelo mau uso de mecanismos tecnológicos que tentam corrigir e adubar solos sem a devida responsabilidade. Ciente das diversas preocupações ambientais em escala global que têm sido ressaltadas em conferências ambientais internacionais (por exemplo, Protocolo de Quioto), empresas transnacionais, em parceria com produtores rurais de suínos na região, passaram a investir nos biodigestores anaeróbios que permitem reduzir a carga orgânica em até $96 \%$, fornecer energia elétrica (biogás) e produzir biofertilizante. A partir dos resultados de pesquisa feita pela Embrapa, a aplicação do biofertilizante no cultivo de café e milho trouxe ganhos de produtividade e eliminação de pragas. Ao analisar o solo após aplicação, foi encontrada grande concentração de agentes químicos prejudiciais ao meio ambiente. Portanto, este artigo objetiva analisar os aspectos positivos e negativos sobre o uso do biofertilizante em solos agrícolas da região do Alto Paranaíba (MG), mais especificamente, dos municípios de Patos de Minas e Patrocínio.
\end{abstract}

Palavras-chave: suinocultura, Alto Paranaíba, biodigestor anaeróbio, biofertilizante.

\section{Abstract}

Since the implementation of the integrated project in pork meat production, the region of Alto Paranaiba (MG) faced a new sector restructuring, which resulted in the installation of several agribusiness companies. However, the region is experiencing a strong environmental impact caused by the accumulation of pig slurry and the misuse of technological mechanisms that attempt to correct and fertilize soils without proper accountability. Aware of the various environmental concerns on a global scale that have been highlighted in international environmental conferences (e.g., Kyoto Protocol), transnational companies, in partnership with pork meat producers from the region, began to invest in anaerobic biodigesters, which allow to reduce the organic load by $96 \%$, providing electrical energy (biogas) and producing biofertilizer. From the results of research done by Embrapa, the application of biofertilizer on the coffee and corn plantation has brought gains in productivity and plague elimination. Analyzing the soil after application, has found harmful high chemical concentrations to the environment. Therefore, this article aims to analyze the positive and negative aspects. This article aims to analyze the use of biofertilizers in agricultural areas of the Alto Paranaiba (MG) region, specifically in the municipalities of Patos de Minas and Patrocinio.

Key words: pork meat production, Alto Paranaiba, anaerobic biodigester, biofertilizers.

\section{Resumen}

Desde la implementación del proyecto integrado en el sector porcino, la región del Alto Paranaiba (MG) ha detectado una nueva reestructuración en el sector, y por lo tanto la instalación de varias empresas de agronegocios. Pero la región está experimentando un fuerte impacto ambiental causado por la acumulación de los purines de 
cerdo y el mal uso de los mecanismos tecnológicos para corregir y fertilizar sin rendición de cuentas adecuada. Conocidos de las diversas preocupaciones ambientales a escala global, a través de la Conferencia Internacional del Medio Ambiente (Protocolo de Kyoto), las empresas transnacionales en asociación con los criadores de cerdos en la región, comenzó a invertir en digestores anaeróbicos, este equipo puede reducir la carga orgánica en un $96 \%$, proporcionan energía eléctrica (biogás) y producir el biofertilizante. Desde los resultados de la investigación realizada por la Embrapa, la aplicación de biofertilizantes en el cultivo del café y el maíz ha traído consigo ventajas de la productividad y la eliminación de plagas. Al analizar el suelo después de la aplicación, encontraron altas concentraciones de productos químicos dañinos para el medio ambiente. Por lo tanto, este artículo pretende analizar el uso de biofertilizantes en las zonas agrícolas en el suelo del Cerrado, en el Alto Paranaíba (MG), delineando los condados de Patos de Minas y de Patrocinio.

Palabras clave: cerdo, El Alto Paranaíba, digestor anaerobio, biofertilizante.

Introdução

Com a implementação do projeto integrado de produção no setor de suínos no final da década de 1980, que tinha como objetivos oferecer treinamentos técnicos intensivos e transformar os proprietários rurais em empresários, empresas nacionais do setor obtiveram resultados positivos na produção e vendas nos mercados interno e externo nos anos posteriores. Diante disso e após alguns estímulos governamentais para o desenvolvimento do cerrado brasileiro, os proprietários rurais ou integrados da região do Alto Paranaíba (MG) passaram a usar meios tecnológicos para aumentar a produção e diversificar os produtos que atendessem às exigências dessas empresas. Em outras palavras, as propriedades rurais passaram a oferecer às empresas mais de um produto que atendiam o mercado e geravam mais receitas (Alves e Cleps, 2003). Entretanto, em razão da combinação entre aumento da produção e diversificação de produtos, o cerrado brasileiro passou a sofrer com o crescente avanço dos impactos negativos no seu solo.

Após a realização de diversas convenções mundiais entre países desenvolvidos e em desenvolvimento sobre o aumento do aquecimento global gerado pelo consumo desenfreado, a Convenção Quadro das Nações Unidas sobre Mudança do Clima e o Tratado de Quioto propuseram o Mecanismo de Desenvolvimento Limpo (MDL) como uma das alternativas para reduzir a emissão de gases de efeito estufa. Dentro deste contexto, os produtores rurais da suinocultura brasileira passaram a receber financiamentos de empresas transnacionais de países desenvolvidos para implantar projetos ambientais em suas propriedades rurais, como no caso do biodigestor anaeróbio, equipamento que, através da introdução do dejeto de suínos, fornece energia (biogás) e produz insumo orgânico (biofertili- 
zante) para a utilização na correção e fertirrigação de diversos cultivos agrícolas. O objetivo da pesquisa que deu origem a este artigo foi analisar o uso do biofertilizante em solos agrícolas da região do Alto Paranaíba, mais especificamente nos municípios de Patos de Minas e Patrocínio.

Materiais e métodos

Área de estudo

A região do Alto Paranaíba, pertencente ao estado de Minas Gerais, possui uma população estimada de 635.916 habitantes, segundo dados do perfil demográfico do estado de Minas Gerais referente ao ano de 2000 (Fundação João Pinheiro, 2003, p. 38). A Figura 1 destaca os municípios de Patos de Minas e Patrocínio inseridos na mesorregião do Triângulo Mineiro/Alto Paranaíba.

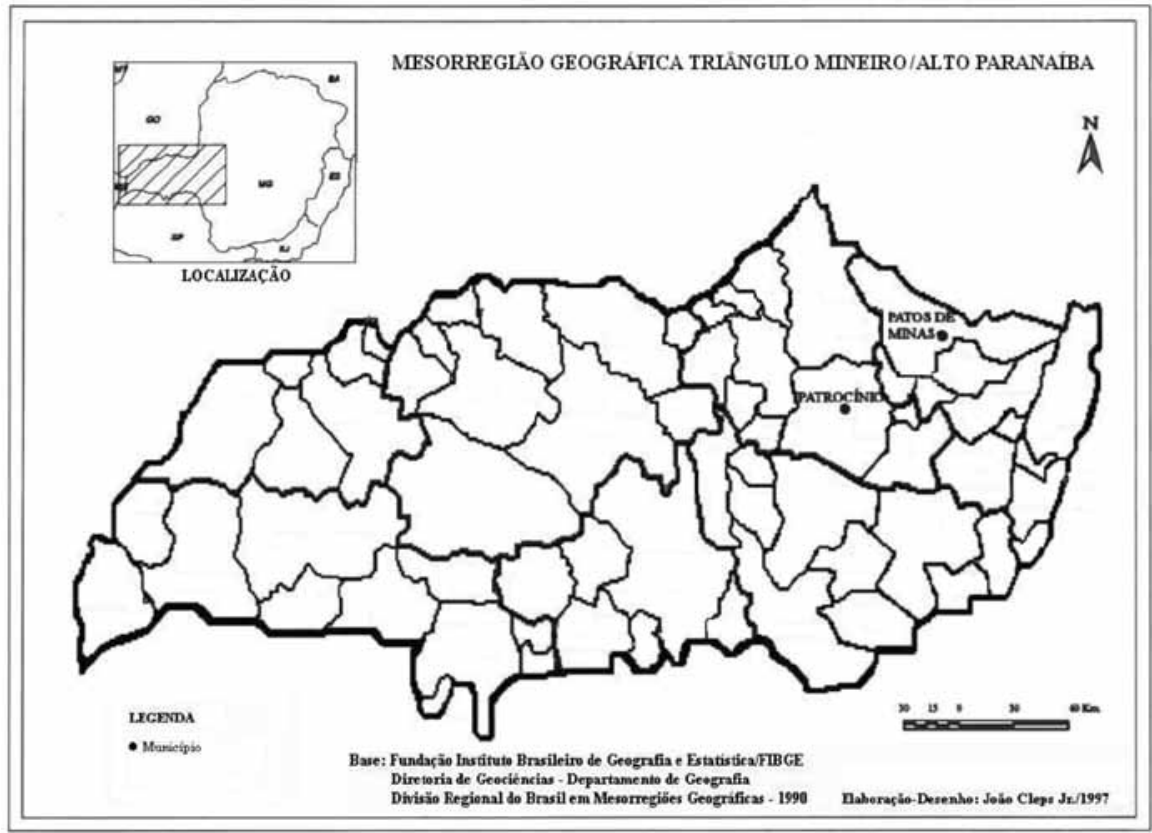

Figura 1 - Localização dos municípios de Patos de Minas e Patrocínio na mesorregião geográfica do Triângulo Mineiro/Alto Paranaíba. Fonte: Silva e Almeida (2001). 
Na área de estudo, ocorre um conjunto de planaltos e chapadas associados à bacia sedimentar do Paraná, fato importante para o funcionamento dos sistemas hidrológicos e, portanto, para o uso de biofertilizantes.

\section{Métodos}

Este estudo foi baseado no levantamento de documentação indireta. Segundo Marconi e Lakatos (2003), este tipo de pesquisa é feito com base na análise de dados contidos em documentos (fontes primárias) e em referências bibliográficas disponíveis como, por exemplo, na internet (fontes secundárias), com o intuito de identificar, localizar, compilar e fichar dados técnicos relacionados à área de estudo.

O estudo foi conduzido com base no levantamento de dados sobre: os projetos do MDL relativos à suinocultura implantada nos municípios em estudo; a implantação e uso do biodigestor anaeróbio na suinocultura; a identificação das formas de uso do biofertilizante em diversas culturas agrícolas; e a identificação dos resultados obtidos sobre os possíveis impactos ambientais nos solos do Cerrado.

\section{Resultados e discussões}

A carne suína vem obtendo ótimos resultados de vendas no setor agropecuário nas últimas décadas em razão do avanço tecnológico porque a produção e variedade têm atendido às exigências dos mercados consumidores interno e externo. Para Sarcinelli, Venturini e Silva (2007, p. 1), "é o consumidor que determina o que o mercado deverá produzir”. Por causa desta determinação, as indústrias alimentícias vêm-se especializando cada vez mais em novas técnicas de produção para atender a este mercado exigente. Segundo o IBGE (2009), a suinocultura brasileira possui um efetivo de 35,9 milhões de cabeças, ocupando a terceira posição mundial. Em termos de quantidade de animais abatidos, o país ocupa a sexta posição, com destaque para a região Sul, que possui o maior efetivo.

A partir da expansão do setor agropecuário decorrente do processo econômico e tecnológico do mercado mundial, a suinocultura mineira, e em especial a suinocultura da região do Alto Paranaíba, passou a exercer um novo padrão produtivo no setor, onde empresas transnacionais e cooperativas de suínos implantaram um modelo denominado de produção 
integrada, que tem como sua característica principal o elevado grau tecnológico e a incorporação rápida ao esquema produtivo. Segundo Miele e Waquil (2007, p. 80), neste sistema de produção, o produtor rural fornece a mão-de-obra, as despesas com energia, água e manejo dos dejetos, enquanto as empresas integradoras fornecem a ração, a assistência técnica, os medicamentos e outros insumos necessários, com o objetivo de manter seu contrato de exclusividade na aquisição do produto final. Em razão desse modelo adotado, a suinocultura do estado de Minas Gerais passou a exercer um grande papel econômico no setor agrícola do país, classificando-se como o quarto maior estado em quantidade de animais abatidos e o primeiro na região Sudeste, com 4.199.138 cabeças (IBGE, 2009).

Como consequência desta expansão, o cerrado brasileiro passou a apresentar uma grave estatística ambiental causada pelo excesso de acúmulo de efluentes líquidos e resíduos sólidos sem tratamento adequado. Os dejetos de suínos não tratados possuem alto poder poluente especialmente para os recursos hídricos. Em termos da Demanda Bioquímica de Oxigênio, nota-se a crescente contaminação das águas dos rios e dos lençóis freáticos, além dos transtornos causados pelo odor e pela concentração de gases de efeito estufa (Furtado, 2007). Para conter este descaso, a Resolução n. 357 do Conselho Nacional do Meio Ambiente (Conama) estabeleceu as condições e padrões de lançamentos de efluentes e de outras providências.

Em 1997, na cidade de Quioto (Japão), 141 países ratificaram um documento, aprovado por consenso, que determinava que os países desenvolvidos (Anexo I) deveriam reduzir a emissão dos gases de efeito estufa em pelo menos 5,2\% do nível de emissão de 1990 até o período entre 2008 e 2012 (Furtado, 2007). Esta obrigação poderia ser parcialmente cumprida mediante a aquisição de títulos de Redução Certificada de Emissões (RCEs) de outros países em desenvolvimento, incluindo o Brasil. Baseado no princípio da "responsabilidade comum, porém, diferenciada", este documento ficou conhecido como Tratado ou Protocolo de Quioto. O país que conseguir esta permissão passa a ter uma meta de redução de emissão maior, enquanto o país comprador terá uma meta de redução de emissão menor. Segundo Souza (2005, p. 17), “as emissões serão as mesmas já que o somatório dessas duas novas metas será o mesmo que o das metas antes da comercialização", fazendo com que haja redução no custo da emissão global. Para potencializar este conceito, o protocolo criou três mecanis- 
mos flexíveis: Implementação Conjunta, Comércio de Emissões, e MDL. Apenas o MDL permite a participação dos países em desenvolvimento, no que se refere à forma de operacionalização dos instrumentos.

Em razão da estrutura da suinocultura brasileira e mineira, diversas empresas se interessaram em investir na tecnologia dos biodigestores anaeróbicos por oferecer ganhos de créditos das reduções certificadas de emissões para o financiamento e as mudanças na prática de manejo, tratamento e utilização dos dejetos de suínos (Konzen, 2005a). No estado de Minas Gerais, o primeiro modelo de biodigestor anaeróbio que atendia à comercialização das RCEs, teve início no ano de 2003, na região do Alto Paranaíba, na Fazenda Becker, localizada no município de Patos de Minas (Konzen, 2005a). Este projeto da Fazenda Becker foi o primeiro projeto de MDL aceito pela Comissão Interministerial de Mudança Global do Clima. Segundo o Cepea (2005), a aceitação foi obtida em $1^{\circ}$ de julho de 2004, com duração de 10 anos, gerando 50.860 RCEs.

Para executar este projeto, as seguintes empresas participaram na elaboração e instalação do biodigestor anaeróbio: AgCert Canadá Co., na condição de financiadora do projeto e com direito de $90 \%$ sobre o valor de "crédito de carbono" durante esses 10 anos; Granja Becker, que permitiu a instalação do biodigestor e possui 10\% do "crédito" gerado; Sansuy S.A. Indústria de Plásticos de São Paulo, que forneceu o material para revestimento do biodigestor; e Iengep Fertirrigação e Biodigestores Ltda de Patrocínio (MG), que instalou e monitora o biodigestor na fazenda (Konzen, 2005a).

A partir do Protocolo de Quioto, diversas empresas do setor de plásticos começaram a desenvolver novos materiais para a construção de biodigestores anaeróbios, com destaque para os biodigestores anaeróbios de modelo japonês, que utilizam mantas plásticas de alta versatilidade e baixo custo (Kunz e Oliveira, 2005). Gaspar (2003, p. 15) definiu os biodigestores anaeróbios como uma câmara fechada para cujo interior dejetos de animais são introduzidos para o interior desta câmara e são fermentados anaerobicamente por bactérias. O biodigestor anaeróbio consegue reduzir a carga orgânica em $87 \%$ (podendo atingir até 96\% quando auxiliado por agentes biorremediadores), além de liberar o biogás e produzir insumos orgânicos (biofertilizante) (Konzen, 2007).

O gás metano, que apresenta entre $60 \%$ e $70 \%$ de sua presença na composição, é o principal componente retirado do sistema de biogás dos 
biodigestores anaeróbios. Segundo Gaspar (2003, p. 45), este gás é incolor, inodoro, altamente combustível e não produz fuligem. Em comunicação pessoal, Konzen (2008) afirmou que, no Brasil, são produzidos aproximadamente 207 milhões de toneladas de resíduos de suínos, liberando grande volume de gás metano na atmosfera, o que por sua vez é 21 vezes mais agressivo do que o gás carbônico.

O biofertilizante derivado dos biodigestores anaeróbios é um efluente líquido que, após a fermentação das bactérias no interior do equipamento, pode alterar beneficamente as propriedades físicas, químicas e biológicas do solo. Pode, ainda, melhorar a capacidade de retenção de água, por ser uma matéria orgânica, além de possuir macronutrientes como nitrogênio $(\mathrm{N})$, fósforo $(\mathrm{P})$ e potássio $(\mathrm{K})$. Como forma de adequação e utilização do biofertilizante nas diversas culturas agrícolas, Konzen (2006, p. 14) ressaltou que é imprescindível o conhecimento da sua qualidade a partir da sua composição, pois o "conhecimento destes valores permite calcular a adubação para cada cultura a ser feita, baseando-se na produtividade pretendida."

Através da análise de laboratório, é possível determinar a quantidade necessária que cada cultura precisa de $\mathrm{N}, \mathrm{P}$ e K para atender às necessidades da produtividade. Diante destes dados obtidos, é possível calcular a quantidade necessária de biofertilizante que irá ser aplicado na cultura desejada. Sendo assim, o Ministério da Agricultura, Pecuária e Abastecimento, através do Art. $2^{\circ}$ da Instrução Normativa Ministerial $\mathrm{n}$. 10, de 6 de maio de 2004, concede as atribuições do uso de biofertilizante na agricultura. Em seu Art. $1^{\circ}$, o biofertilizante foi definido como um produto que possui princípio ativo ou agente orgânico isento de substâncias agrotóxicas, sem considerar o seu valor hormonal ou estimulante que pode elevar a produtividade.

O Art. $3^{\circ}$ do Capítulo 3 define as garantias e especificações do biofertilizante quanto à sua natureza física, podendo ele ser ser fluido ou sólido. Os produtos sólidos constituem-se de partículas ou frações sólidas que podem estar na forma de granulado, pó, farelado ou farelado grosso. Os casos que não atenderem às granulometrias especificadas, deverão constar, no produto, a expressão "produto sem especificação granulométrica”. Para os produtos do tipo fluido, que deverão ser apresentados no estado de solução ou suspensão, ou seja, que deverão possuir pelo menos uma fase líquida, será obrigatória a indicação da sua densidade, garan- 
tias em percentagem mássica e sua massa por volume. Desta forma, os produtos fluidos ficam definidos como: solução verdadeira (solução com ausência de sólido), suspensão homogênea (dispersão composta de uma fase líquida) e suspensão heterogênea (dispersão composta de pelo menos uma fase líquida).

Konzen (2007, p. 6) mostrou que os primeiros resultados da aplicação do biofertilizante na região do Alto Paranaíba foram observados em culturas de milho e café, no município de Patrocínio (MG), onde a transferência foi feita via motor a gasolina adaptada para o biogás e a sua distribuição por autopropelido (motor diesel-biogás). Segundo dados do Censo Agropecuário de 2006 (IBGE, 2009), o município de Patrocínio possui 86.625 cabeças de suínos, posicionando-se como o sexto maior município em número de efetivos do estado de Minas Gerais. Entretanto, é possível notar a presença de diversas empresas de frigorífico do setor na região, o que torna o município um dos maiores abatedores de carne suína do estado.

O município de Patos de Minas possui 155.161 cabeças de suínos, tornando-se o segundo maior efetivo do estado de Minas Gerais. Por causa desta situação, as três principais empresas de genética suína do país instalaram-se neste município, tornando-o um polo de biotecnologia do setor (IBGE, 2009).

Um estudo sobre aplicação de biofertilizante na cultura de café, conduzido pela Embrapa Milho e Sorgo em Patos de Minas (MG), mostrou que houve, no período de 2005 a 2008, um aumento de $15 \%$ na produtividade de café em uma região onde a boa produtividade ocorre a cada dois anos por causa da sazonalidade, salvo condições climáticas adversas (Konzen, 2009). Neste estudo, a produção passou de 35 sacas/ha em 2005 para 45 sacas/ha em 2008 (Gráfico 1), para uma aplicação de 180 a 210 $\mathrm{m}^{3}$ de biofertilizante por hectare. Nesse período de tempo, durante trinta dias, o biofertilizante serviu como um bioinseticida, levando à eliminação da praga do bicho-mineiro após três aplicações de 600 litros/hectares de biofertilizante, combinados com 40 litros de um produto inseticida.

Um outro estudo que pode ser destacado foi o conduzido pela Embrapa Milho e Sorgo no município de Rio Verde, Goiás, no período de 2000 a 2005. Neste caso, foi aplicado biofertilizante na cultura de milho, em diversas doses exclusivas e combinadas com adubação química no solo do tipo Latossolo Vermelho-Amarelo (Konzen, 2006, p. 16). A dose 
utilizada de biofertilizante na propriedade foi de $50 \mathrm{~m}^{3}$, tendo como resultado a produção aproximada de $7.000 \mathrm{~kg}$ de milho por hectare, o que equivale à produtividade média da região. Ao desejar uma aplicabilidade mais econômica, Konzen (2006, p. 20) recomendou a aplicação do biofertilizante através da aspersão e por tanque tratorizado em propriedades de até 24 hectares, pois os custos são equivalentes. Porém, à medida que a área fertilizada cresce, a opção por aspersão se torna mais rentável em até $52,6 \%$, se comparada ao uso do tanque tratorizado. Desta forma, o produtor, ao aplicar biofertilizante em cultivos de milho, entre $50 \mathrm{~m}^{3}$ e $100 \mathrm{~m}^{3}$ por hectare, obtém uma rentabilidade entre $47 \%$ e $48 \%$. Isto significa que, a cada real aplicado na produção de milho com dejetos de suínos, o produtor recebe de volta entre R\$1,47 e R\$ 1,48 (Konzen, 2006, p. 20).

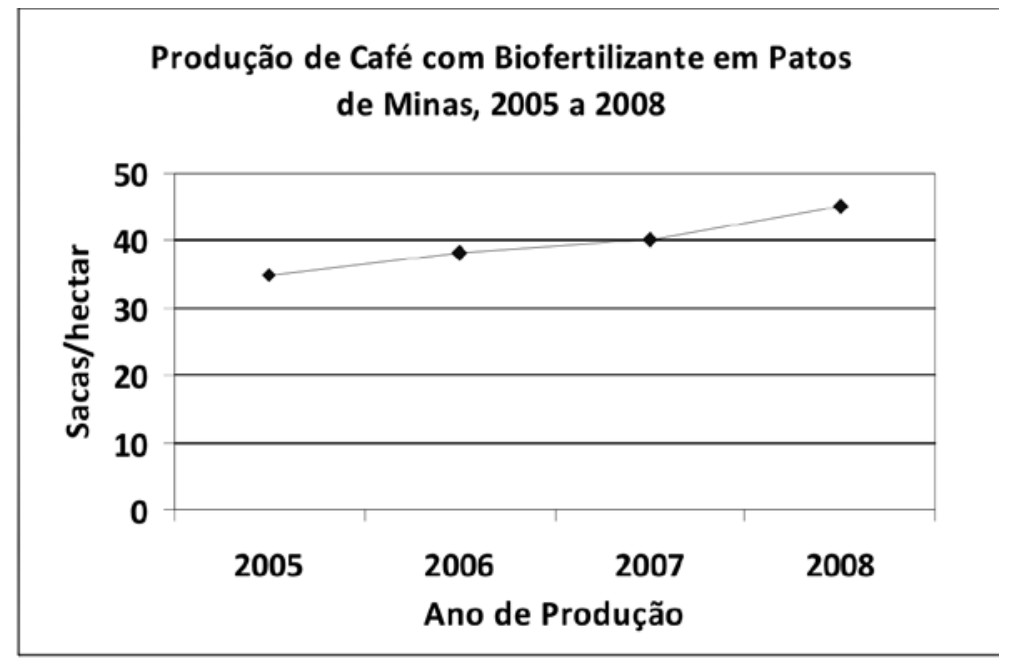

Gráfico 1 - Produção de café com biofertilizante em Patos de Minas, no período de 2005 a 2008.

Fonte: Konzen (2009).

No entanto, é importante ressaltar que, de acordo com Konzen e Alvarenga (2005, p. 13), houve um aumento na concentração de zinco e cobre nos solos utilizados nesse último estudo, revelando que esses agentes químicos, se aplicados em altas concentrações, podem atingir os mananciais de água por causa de sua movimentação em profundidade no perfil de solo, além de ser altamente prejudiciais à saúde humana e animal. 
Segundo Seganfredo (2007 p. 1), já existem resultados de pesquisas desenvolvidas em várias partes do Brasil que mostram que o biofertilizante derivado dos biodigestores anaeróbios de suínos corresponde a um composto orgânico potencialmente poluente. Este autor afirmou ainda que até mesmo a concepção de "insumo barato" merece reavaliação, além de que existe o risco da aplicação de grandes quantidades de biofertilizantes. Em razão de que os solos do Brasil Central favorecem o processo de lixiviação, grande parte dos nutrientes aplicados pelos dejetos suínos pode atingir o lençol freático. Vale ressaltar que o biofertilizante é passivo de produção em escala industrial para atender à demanda do mercado.

Diante disso, tanto Konzen e Alvarenga (2005, p. 14) como Seganfredo (2007, p. 6) defendem a aplicação de doses equivalentes às necessidades de cada cultura para minimizar o risco ambiental. Isto é possível por meio de planos de manejo de nutrientes compatíveis com o tipo de solo e planta e de orientações técnicas que levem em consideração a aptidão de uso do solo. A elaboração de um plano de uso com duração mínima de quatro anos para observar a concentração de nutrientes nos dejetos constitui-se em um outro valioso instrumento de auxílio ao cumprimento das legislações ambientais vigentes e à preservação ambiental.

\section{Considerações finais}

Como forma de atender às necessidades do mercado agrícola, o biofertilizante se apresentou como um insumo agrícola eficaz na recuperação e no melhoramento do solo, agregando assim uma melhor qualidade ao produto e, consequentemente, trazendo um aumento de produção nas safras posteriores ao primeiro ano aplicado. Com isso, o biofertilizante se tornou um insumo desejado e requisitado entre os proprietários rurais e empresas do setor do agronegócio, que o aplicam sem a devida orientação profissional e análise técnica em diversas culturas agrícolas.

O aspecto negativo do uso de biofertilizantes é o descaso dos proprietários rurais que, por falta de informação despejam biofertilizantes em rios e em terrenos próximos às áreas agrícolas sem o devido cuidado. Dessa forma, fica clara a necessidade de realização de pesquisas que possam treinar profissionais da área para auxiliar os proprietários rurais e empresas do setor quanto aos riscos e benefícios que o biofertilizante traz ao solo ou às culturas agrícolas. 


\section{Referências}

ALVES, R. R.; CLEPS JÚNIOR, J. Novas ruralidades no desenvolvimento agrícola do Triângulo Mineiro: perfil da agricultura familiar nos anos 90. Revista Horizonte Científico, Uberlândia (MG), v. 2, n. 2, p. 1-28, 2003.

CEPEA. Centro de Estudos Avançados em Economia Aplicada. Estatísticas e Informações sobre o Mercado de Carbono, 2005. Disponível em: <http://www.cepea. esalq.usp.br/economiaambiental/files/2005/11nov.pdf>. Acesso em: 1 dez. 2008.

FUNDAÇÃO JOÃO PINHEIRO. Centro de Estatística e Informações. Perfil Demográfico do estado de Minas Gerais 2000. Belo Horizonte: Fundação João Pinheiro, 2003. 111p.

FURTADO, P. G. O Uso de biodigestores como opção rentável para o tratamento de dejetos de suínos. Fortaleza, 2007. Disponível em: <http://www.pecnordeste. com.br/pec2008/pecnordeste/doc/suinocultura/Paulo\%20Guilherme\%20Furtado. pdf >. Acesso em: 03 jul. 2008.

GASPAR, R. M. B. L. Utilização de biodigestores em pequenas e médias propriedades rurais com ênfase na agregação de valor: um estudo de caso na região de Toledo-PR. Florianópolis, 2003. 106f. Dissertação (Mestrado em Engenharia de Produção) - Programa de Pós-Graduação em Engenharia de Produção, Universidade Federal de Santa Catarina (UFCS). Disponível em: < http://www.tede.ufsc. br/teses/PEPS4022.pdf>. Acesso em: 3 jul. 2008.

IBGE - Instituto Brasileiro de Geografia e Estatística. Censo demográfico de 2006. Brasília: IBGE, 2009. Disponível em: <http://www.ibge.gov.br>. Acesso em: 15 jun. 2009.

KONZEN, E. A. Dejetos de suínos fermentados em biodigestores e seu impacto como insumo agrícola. In: SIMPÓSIO GOIANO DE AVICULTURA, 7, SIMPÓSIO GOIANO DE SUINOCULTURA, 2, AVESUI CENTRO-OESTE SEMINÁRIOS TÉCNICOS DE SUINOCULTURA, 2005. Goiânia: Embrapa Suínos e Aves, 2005a. Disponível em: <http://www.cnpsa.embrapa.br/index.php?ids=Sn6l70p1l\&idl=\& $\mathrm{pg}=8 \&$ area $=2>$. Acesso em: 15 jun. 2009.

KONZEN, E. A.; ALVARENGA, R. C. Manejo e utilização de dejetos animais: aspectos agronômicos e ambientais. Documentos/Embrapa Milho e Sorgo (Sete Lagoas-MG), 2005. Disponível em: <http://www.cnpms.embrapa.br/publicacoes/ publica/2005/circular/Circ_63.pdf>. Acesso em: 15 jun. 2009.

KONZEN, E. A. Viabilidade ambiental e econômica de dejetos de suínos. Documentos/Embrapa Milho e Sorgo (Sete Lagoas-MG), 2006.

KONZEN, E. A. Aproveitamento energético e biogás: a experiência da suinocultura no tratamento de efluentes. In: CONGRESSO BRASILEIRO DE ENGENHARIA SANITÁRIA E AMBIENTAL, 24, 2007, Belo Horizonte. Disponível em: $<$ http://www.abes.locaweb.com.br/XP/XP-EasyPortal/Site/XP-PortalPaginaShow. php?id=457>. Acesso em: 15 jun. 2009.

KONZEN, E. A. Sistemas integrados: manejo e utilização de dejetos de suínos. Patrocínio, comunicação pessoal no Sítio do Cedro, em 23 de junho de 2008. 
KONZEN, E. A. Uso sustentável de nutrientes na cafeicultura. In: ENCONTRO NACIONAL DE IRRIGAÇÃO DA CAFEICULTURA NO CERRADO, 14, 2009, Araguari. Palestra FENICAFÉ.

KUNZ, A.; PERDOMO, C. C.; OLIVEIRA, P. A. V. de. Biodigestores: avanços e retrocessos. Revista Suinocultura Industrial, ed. 178, n. 4, ano 26, 2004. Disponível em: <http://www.suinoculturaindustrial.com.br/PortalGessulli/WebSite/ Edicao/1181,2004,9085,informe-embrapa-biodigestores-avancos-e-retrocessos. aspx>. Acesso em: 3 jul. 2008.

MIELE, M.; WAQUIL, P. D. Cadeia produtiva da carne suína no Brasil. Revista de Política Agrícola, ano XVI, n. 1, 2007, p. 75-87. 2007. Disponível em: <http://www. embrapa.br/publicacoes/tecnico/revistaAgricola/rpa-de-2007/REv.\%20Pol.\%20 Agr.\%2001-2007.pdf>. Acesso em: 25 set. 2009.

MARCONI, M. A.; LAKATOS, E. M. Fundamentos da metodologia científica. 5. ed. São Paulo: Atlas, 2003. 320p.

SARCINELLI, M. F; VENTURINI, K. S; SILVA, L. C. Processamento da carne suína. In: Boletim Técnico. Vitória: UFES, 2007. Disponível em: <http://64.233.163.132/ search?q=cache:3cCLWRCPfZkJ:www.agais.com/telomc/b01907_processamento_suinos.pdf+qualiddae + da + carne + suina \&cd=2\&hl=pt-BR\&ct $=$ clnk\&gl=br $>$. Acesso em: 31 ago. 2009.

SEGANFREDO, M. A. Os dejetos de suínos e seus riscos ambientais no uso como fertilizante. Concórdia (SC): Embrapa Suínos e Aves, 2007. Anais eletrônicos... Disponível em: <www.cnpsa.embrapa.br/down.php?tipo=artigos\&cod_artigo=296 $>$. Acesso em: 31 ago. 2009.

SILVA, P. J.; ALMEIDA, M. G. Territorialidade e desterritorialidade: os assentamentos rurais e a reterritorialidade do campesinato no espaço agrário do cerrado mineiro. In: CONGRESSO DE CIÊNCIAS HUMANAS, LETRAS E ARTES, V, 2001, Ouro Preto. Anais. Disponível em: <www.ichs.ufop.br/conifes/anais/MPC/ mpc0604.htm>. Acesso em: 16 jun. 2009.

SOUZA, P. F. M. Metodologias de monitoramento de projetos de MDL: uma análise estrutural e funcional. Rio de Janeiro, 2005. Dissertação (Mestrado em Ciência em Planejamento Energético) - Programa de Pós-Graduação de Engenharia, Universidade Federal do Rio de Janeiro (Coppe/UFRJ). Disponível em: <http://www.ppe. ufrj.br/ppe/production/tesis/pfernandez.pdf>. Acesso em: 3 jul. 2008.

Rodrigo Cavalcanti do Nascimento - Possui graduação em geografia pela Universidade Federal de Uberlândia e faz curso de Especialização (Lato sensu) em Gestão Ambiental, pela Faculdade Católica de Uberlândia.

Recebido para publicação em junho de 2010 Aceito para publicação em setembro de 2010 